JOURNAL of

MAINE MEDICAL CENTER Journal of Maine Medical Center

\title{
Effectiveness of Two Frequently Used Screening Tools in Identifying Depression and Anxiety in Collegiate Athletes
}

\author{
Adriana C. Isacke DO \\ Maine Medical Partners
}

Et al.

Follow this and additional works at: https://knowledgeconnection.mainehealth.org/jmmc

Part of the Behavioral Medicine Commons, Family Medicine Commons, Internal Medicine Commons, Medical Humanities Commons, Orthopedics Commons, Other Mental and Social Health Commons, Psychiatric and Mental Health Commons, Sports Medicine Commons, and the Sports Sciences Commons

\section{Recommended Citation}

Isacke, Adriana C. DO; Haskins, Amy PhD; Holt, Christina MD, MSc; and Dexter, Williams MD, FACSM (2021) "Effectiveness of Two Frequently Used Screening Tools in Identifying Depression and Anxiety in Collegiate Athletes," Journal of Maine Medical Center. Vol. 3 : Iss. 1 , Article 3.

Available at: https://knowledgeconnection.mainehealth.org/jmmc/vol3/iss1/3 https://doi.org/10.46804/ 2641-2225.1068

The views and thoughts expressed in this manuscript belong solely to the author[s] and do not reflect the opinions of the Journal of Maine Medical Center or MaineHealth.

This Original Research is brought to you for free and open access by Maine Medical Center Department of Medical Education. It has been accepted for inclusion in the Journal of Maine Medical Center by an authorized editor of the MaineHealth Knowledge Connection. For more information, please contact Dina McKelvy mckeld1@mmc.org.

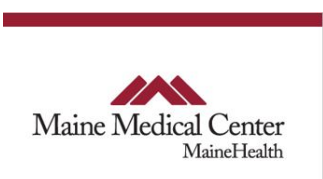


Effectiveness of Two Frequently Used Screening Tools in Identifying Depression and Anxiety in Collegiate Athletes

\section{Authors}

Adriana C. Isacke DO; Amy Haskins PhD; Christina Holt MD, MSc; and Williams Dexter MD, FACSM 


\title{
Effectiveness of Two Frequently Used Screening Tools in Identifying Depression and Anxiety in Collegiate Athletes
}

\author{
Adriana Isacke, DO, ${ }^{1}$ Amy Haskins, $\mathrm{PhD},{ }^{2}$ Christina Holt, MD, MSc, ${ }^{2}$ William Dexter, MD, FACSM ${ }^{1}$ \\ ${ }^{1}$ Maine Medical Center Sports Medicine, South Portland, ME, ${ }^{2}$ Maine Medical Center Department of Family Medicine, \\ Portland, ME
}

Introduction: $\quad$ To determine whether the Electronic Pre-participation Physical Examination (EPPE), a proprietary and frequently used tool, is an effective method for depression and anxiety screening in the collegiate athlete population as compared to the Patient Health Questionnaire-4 (PHQ-4).
Methods: $\quad$ College athletes at a Division III university completed PHQ-4 questionnaires and a proprietary EPPE. Positive reponse rates to depression and/or anxiety for both questionnaires were collected and analyzed

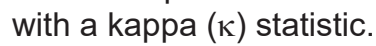
Results: $\quad$ Among 420 students, we found that $9(2 \%)$ reported depression and/or anxiety via the EPPE. Of the 26 students $(6 \%)$ who answered positively on the PHQ-4, we found that 2 reported depression and/ or anxiety on the EPPE. Of the 9 students who reported a history of depression and/or anxiety on the EPPE, we found that 2 scored positively on the PHQ-4. Agreement between the 2 methods was poor ( $\kappa$ $=0.08)$.

Discussion: $\quad$ Reporting depression or anxiety among collegiate athletes with the EPPE screening question related to the nervous system is low compared to the PHQ-4.

Conclusions: $\quad$ Colleges should consider adding additional depression and anxiety screening tools during the preparticipation exam to ensure they identify and treat at-risk student athletes.

Keywords: $\quad$ depression, athletes, anxiety, EPPE

A dolescent rates of depression and suicide are startlingly high: $30.7 \%$ of adolescents report feeling so depressed that it was difficult to function, and $48.4 \%$ report experiencing overwhelming anxiety. ${ }^{1}$ There are inconsistencies in the literature about depression rates in college athletes versus non-athletes. Some report lower rates in athletes, some report no difference, and others report rates as high as $23.7 \%^{2,3,4}$ Despite the known benefits of exercise on mental health, several risk factors for depression in athletes have been quoted in the literature, including self-reported pain, freshman status, female sex, and stress from academic and athletic demands..$^{3,4}$ Student athletes have identified higher levels of negative emotional

Correspondence: Adriana Isacke, DO

Maine Medical Center Sports Medicine Fellowship 119 Gannett Drive, South Portland, ME 04106 isacka@mmc.org states, sleep disturbances, loss of appetite, mood disturbances, decreased interest in training/ competition, reduced self-confidence, and declined ability to concentrate. ${ }^{5}$

Several questionnaires have been used to identify college students, specifically athletes, at risk for depression. However, there are few studies identifying the optimal way to reach athletes to ensure the most accurate assessment of their mental health status and risk factors. ${ }^{6}$ Because athletes at serious risk of depression or suicide may go unrecognized, it is important to have a tool that effectively identifies those at highest risk. Kroshus conducted a cross-sectional study of collegiate sports medicine departments and found that there is high variability in institutional screening practices for college athletes, with higher rates of screening in Division I athletics. ${ }^{7}$ 
Privit Profile ${ }^{\mathrm{TM}}$ is a widely used online Electronic Pre-Participation Examination (EPPE) developed by Privit $^{\text {TM }}$. The EPPE includes a single question about a variety of neurological symptoms, including depression, but it has not been validated in the general or college athlete populations. The EPPE is a required questionnaire for college athletes to complete before starting the academic year. Despite the concern that the neurologic symptom question may under-identify athletes at risk for depression and/or anxiety, not all schools are using a supplemental questionnaire for mental health screening. As the Patient Health Questionnaire-4 (PHQ-4) is validated to detect major depression in adults, it may be a better tool for identifying at-risk athletes early. Although the PHQ-4 has not been validated in the adolescent population, it appears to have similar sensitivity and specificity to the PHQ-2, which has been validated in the adolescent population..$^{8,9}$ Based on this correlation, we believed the PHQ-4 would be appropriate to use with college athletes.

The aim of this study was to determine whether rates of depression and/or anxiety reported to the EPPE neurological question correlated with the rates reported on the PHQ-4 in a college athlete population. Our objective was to determine if the EPPE alone could effectively screen for depression and/or anxiety in this population or if other validated screening tools should be added to the preparticipation exams.

\section{METHODS}

During the 2013-2014 academic year, athletes at a Division III University completed Paper Wellness Screening forms, including the PHQ4 , as part of their pre-participation clinical exam administered at the start of the fall semester. The PHQ-4 questions included responses to the frequency of experiences in the last 2 weeks, including: (1) feeling nervous, anxious, or on edge; (2) not being able to stop or control worrying; (3) little interest or pleasure in doing things; and (4) feeling down, depressed, or hopeless. The athletes could choose from the following answers: "not at all," "several days," "more than half the days," or "nearly every day." These forms were filed as part of the student health record. In addition, all athletes were required to complete a forced-choice EPPE using the confidential vendor software program Privit $^{\mathrm{TM}}$. The depression-screening question on this questionnaire is under the nervous system https://knowledgeconnection.mainehealth.org/jmmc/vol3/iss $1 / 3$ category and worded as follows: "Past history of stroke or transient ischemic attack (TIA), frequent or severe headaches, dizziness, blackouts, seizure disorder (epilepsy), depression, anxiety attacks, muscle weakness, nerve tingling, loss of sensation, muscle cramps or chronic fatigue?" If the student checked "yes," they were then asked, "What was/ is the problem?" Students types answers into an open-ended text box. These forms also became part of the student's health record.

This research was deemed exempt by the Maine Medical Center Institutional Review Board. The university provided team rosters for the 2013-2014 academic year, and we reviewed all health records and abstracted responses to the Wellness Screening and Privit $^{\mathrm{TM}}$ depression-screening questions. We also collected the age, sex, and race of the student. The data were saved in a de-identified manner in a password-protected Excel spreadsheet, which was saved on a secure, HIPPA-compliant network drive.

We tabulated the age, sex, and race of all athletes. For all students who answered "yes" to the neurologic question in the EPPE, we manually examined the open-ended responses. We classified those who wrote in "depression" or "anxiety" (or both) as self-reporting a history of depression/anxiety. We scored the PHQ-4 to create validated categories as follows: none (0-2), mild (3-5), moderate (6-8), and severe (9-12). Due to 0 responses in the severe category and sparse numbers in the moderate category, we collapsed the categories to negative or positive. We used chi-square tests or Fisher's exact tests to compare age, sex, and race by depression status. We then created a 2-by-2 table comparing the classification of positive answers to depression and/or anxiety questions between the PHQ-4 and EPPE. The kappa ( $\kappa)$ statistic was then calculated to compare agreement of the 2 tests.

\section{RESULTS}

Out of 478 student athletes, a total of 420 (87.9\%) answered both the EPPE question and the PHQ-4. Athlete age ranged from 17 to 18 years (33\%), 18 to 20 years $(42 \%)$, and 21 years or older $(25 \%)$. Student groups were roughly equal by sex $(54 \%$ male and $46 \%$ female). Most athletes self-reported as white (92\%).

Sixteen athletes (3.8\%) answered "yes" to the neurologic question in the EPPE, with $9(2 \%)$ selfreporting depression and/or anxiety. Age and race 
were not associated with depression or anxiety. The diagnoses were more common among females $(3.6 \%)$ than males $(0.8 \%)$, although the difference was not significant (Fisher's exact; $P=.09$ ).

On the PHQ-4, we found that 24 athletes scored as in the mild category (5.7\%) and 2 scored in the moderate category $(0.5 \%)$. Scoring mild/moderate did not differ by sex or race, but it was more common among athletes aged 17 to 18 years (5.8\%) and 19 to 20 years $(9.6 \%)$ than among those 21 years and older $(1.0 \%)(P=.01)$.

The association between scoring positively on the PHQ-4 and reporting a history of depression/ anxiety on the EPPE screen is detailed in Table 1. Of the 26 students scoring positively on the PHQ4 , only $2(8 \%)$ reported depression/anxiety on the EPPE. Conversely, of the 9 students who reported a history of depression/anxiety on the EPPE, only $2(22 \%)$ scored positively on the PHQ-4. Overall agreement between the 2 methods was poor $(\kappa=$ 0.08).

\section{DISCUSSION}

Our study demonstrates that reporting depression/ anxiety with the EPPE and PHQ-4 depressionscreening questions among these college athletes is low compared to the previously quoted $30.7 \%$. $^{1}$ Approximately $6 \%$ of studentathletes who completed the PHQ-4 screened positive for depression, which is less than expected. Even fewer students reported a history of depression/anxiety on the EPPE $(2 \%)$, and there was very poor concordance between the EPPE and PHQ-4. Despite low positivity rates on both screens, the PHQ-4 captured more atrisk athletes than the EPPE. Our study supports previous claims that freshman and female college students reported more symptoms of depression $\left(3.4 \%\right.$ and $3.9 \%$, respectively). ${ }^{3}$ It also supports the concern that the EPPE neurologic question is not an effective screening tool for depression in this population. ${ }^{12}$ The National Strength and Conditioning Association calls for additional mental health screening during pre-participation physicals to ensure mental health disorders are adequately identified in athletes.

There are a number of possible reasons the tools under-identified depression and anxiety in athletes. For example, the format of the EPPE's depression question embeds acknowledgment of symptoms of depression in a broader neurologic question. This may lead to misunderstanding or misclassification. Also, the questions being asked in the PHQ-4 do not relate to depression and anxiety manifestations in this population. Esfandiari et al. suggested that depressive symptoms are different for college athletes than the general population. ${ }^{10}$ Khawaja et al. developed a different tool for in-depth evaluation of college students because they felt one could not guage depression in students based on appetite or sleep loss, as these symptoms are common among all students and do not herald depression. ${ }^{11}$ Khawaja also stated that motivational problems, pessemism, self-blame, self-dislike, lack of concentration, and lack of energy are common among depressed college students and are not queried in the screening tools. Although this tool developed by the researchers seems to target symptoms that are more specific to college students, its length is not practical to use as a screening tool. Because the $\mathrm{PHQ}-4$ identified more athletes at risk for depression and/or anxiety, it may be a better screening tool for this population than other tools currently used.

Table 1. Association between scoring mild/moderate on PHQ-4 and reporting depression/ anxiety on the EPPE $(n=420)$.

\begin{tabular}{|c|c|c|c|}
\hline & & \multicolumn{2}{|c|}{$\begin{array}{l}\text { EPPE depression/anxiety } \\
\text { (self-reported) }\end{array}$} \\
\hline & & No & Yes \\
\hline & Total & 411 & 9 \\
\hline \multicolumn{4}{|l|}{ PHQ-4 form } \\
\hline Negative & 394 & 387 & 7 \\
\hline Positive & 26 & 24 & 2 \\
\hline
\end{tabular}




\section{Strengths and limitations}

Our study used current screening tools that are available to screen for anxiety and depression. The student athletes attended a school that had well-established behavioral health support, which made for easy follow up. Our access to the student athletes through the pre-participation physicals allowed us to directly compare the same individual's response. The differences between the tools may have led to some limitations. The PHQ-4 aims to identify persons who have experienced symptoms within the last 2 weeks, whereas the EPPE asks about a history of depression or anxiety. Still, it is important to examine the concordance between these responses because the EPPE is currently the only tool used to capture depression and/or anxiety among athletes at this university. Also, similar to standard pre-participation screening, the EPPE is generally completed weeks before the start of school year. The mode of administration for each survey was also different. The paper versus electronic administration could have affected a student's willingness to respond accurately. In addition, the time of year the surveys were administered may have affected the low positive rate. The surveys were completed after summer break, before school and just after the athletic season started. Depression rates during the summer months may be lower and then increase during the academic year as school and athletic pressures begin to rise. Finally, small numbers of non-white students limits our ability to distinguish any differences based on race.

\section{CONCLUSIONS}

This study supports that the mental health screening question used on the EPPE under-identifies students at risk for depression and anxiety compared to the validated PHQ-4, although both rates were low in the college athlete population. Colleges should consider adding additional depression and anxiety screening tools during the pre-participation exam to ensure they identify and treat at-risk student athletes. Further research is needed to determine the most appropriate methods of screening the college athlete population for depression and anxiety. Future studies might focus on assessing depression and anxiety among student athletes during the academic semester, when stressors are likely higher than during the pre-season.

\section{Conflicts of Interest: None REFERENCES}

1. Unwin BK, Goodie J, Reamy BV, Quinlan J. Care of the college student. Am Fam Physician. 2013; 88(9):596-604. Accessed April 07, 2016. https://www.aafp.org/afp/2013/1101/p596.html

2. Armstrong S, Oomen-Early J. Social connectedness, selfesteem, and depression symptomatology among collegiate athletes versus nonathletes. $J$ Am Coll Health. 200957(5):521526. doi:10.3200/JACH.57.5.521-526

3. Yang J, Peek-Asa C, Corlette JD, Cheng G, Foster DT, Albright J. Prevalence of and risk factors associated with symptoms of depression in competitive collegiate student athletes. Clin J Sport Med. 2007;17(6): 481-487. doi:10.1097/ JSM.0b013e31815aed6b

4. Wolanin A, Hong E, Marks D, Panchoo K, Gross M. Prevalence of clinically elevated depressive symptoms in college athletes and differences by gender and sport. $\mathrm{Br} J$ Sports Med. 2016;50(3):167-171. doi:10.1136/bjsports-2015-095756

5. Neal TL, Diamond $\mathrm{AB}$, Goldman $\mathrm{S}$, et al. Interassociation recommendations for developing a plan to recognize and refer student-athletes with psychological concerns at the secondary school level: a consensus statement. J Athl Train. 2015;50(3):231-249. doi:10.4085/1062-6050-50.3.03

6. Shean G, Baldwin G. Sensitivity and specificity of depression questionnaires in college-age sample. J Genet Psychol. 2008;169(3):281-288. doi:10.3200/GNTP.169.3.281-292

7. Kroshus E. Variability in institutional screening practices related to collegiate student-athlete mental health. J Athl Train. 2016;51(5):389-397. doi:10.4085/1062-6050-51.5.07

8. Richardson LP, McCauley E, Grossman DC, et al. Evaluation of the Patient Health Questionnaire-9 Item for detecting major depression among adolescents. Pediatrics. 2010;126(6):11171123. doi:10.1542/peds.2010-0852

9. Löwe B, Wahl I, Rose M, et al. A 4-item measure of depression and anxiety: validation and standardization of the Patient Health Questionnaire-4 (PHQ-4) in the general population. J Affect Disord. 2010;122(1-2):86-95. doi:10.1016/j.jad.2009.06.019

10. Esfandiari A, Broshek DK, Freeman JR. Psychiatric and neuropsychological issues in sports medicine. Clin Sports Med. 2011;30(3):611-627. doi:10.1016/j.csm.2011.03.002

11. Khawaja NG, Bryden KJ. The development and psychometric investigation of the university student depression inventory. $J$ Affect Disord. 2006;96(1-2):21-29. doi:10.1016/j. jad.2006.05.007

12. Gearity B, Moore E, Whitney G. National Strength and Conditioning Association's Endorsement of the National Collegiate Athletic Association Sport Science Institute's "Mental Health Best Pratices: Inter-Association Consensus Document: Best Practices for Understanding and Supporting Student-Athlete Mental Health Wellness." Strength Cond Jl. 2017;39(4):1-3. doi:10.1519/SSC.0000000000000314 